\title{
Bilateral anterior ischemic optic neuropathy after bilateral neck dissection
}

This article was published in the following Dove Press journal:

Clinical Ophthalmology

25 February 2010

Number of times this article has been viewed

\author{
María J Suárez-Fernández \\ Antonio Clariana-Martín \\ Enrique Mencía-Gutiérrez \\ Esperanza Gutiérrez-Díaz \\ Teresa Gracia-García-Miguel \\ Ophthalmology Department, \\ 12 de Octubre Hospital, \\ Complutense University, \\ Madrid, Spain
}

Correspondence: Enrique Mencía-Gutiérrez Cedro, 23 E28250 Torrelodones,

Madrid, Spain

Tel +34 67 67I II02

Fax +34 913908358

Email emencia.hdoc@salud.madrid.org
Purpose: The risk of visual loss after nonocular surgeries is very low, between $0.2 \%$ and $4.5 \%$. According to the American Society of Anesthesiologists, ischemic optic neuropathy has been reported mostly after spinal surgery $(54.2 \%)$, followed by cardiac surgery and radical neck dissection (13.3\%). It may occur in association with some conditions that include systemic hypotension, acute blood loss and hypovolemia.

Case report: A 46-year-old woman, whose diagnosis was laryngeal squamous cell carcinoma, complained of visual loss in her right eye two days after surgery (laryngectomy with bilateral radical neck dissection and left jugular ligature) and one day later in her left eye. The diagnosis was nonarteritic anterior ischemic optic neuropathy.

Conclusion: Anterior ischemic optic neuropathy related to nonocular surgery is usually bilateral and its prognosis is very poor, resulting in blindness or severe visual loss. Although rare, patients should be warned about this complication, which has a profound impact on quality of life, since no therapeutic measure, including correction of hypotension and anemia, seems to improve the prognosis of this complication.

Keywords: ischemic optic neuropathy, visual loss, radical neck dissection, blood loss

\section{Introduction}

Postoperative visual loss (POVL) following general anesthesia during nonocular surgery is a rare, but devastating complication with an estimated incidence of between $0.2 \%$ and $4.5 \%$ depending on the type of surgery. ${ }^{1}$ The lesion can occur at the level of the cornea (the most common), retina, optic nerve, or occipital cortex. ${ }^{2}$

Ischemic optic neuropathies (ION) are now the most frequently reported condition associated with permanent POVL. ${ }^{3}$ The deterioration of vision generally occurs immediately after surgery and progresses in two or three days. Risk factors include combinations of prolonged surgical times, hypotension, anemia due to blood loss, and prone positioning. ${ }^{4}$ According to the American Society of Anesthesiologists (ASA) POVL Registry, ${ }^{5}$ ION has been reported most frequently after spinal surgery (54.2\%), followed by cardiac surgery and radical neck dissection (13.3\%). Following cardiac procedures, anterior ION (AION) appears to be more common than posterior ION (PION), whereas following spinal surgery and radical neck dissections, PION is the predominating clinical form. ${ }^{3}$

AION is an uncommon complication of head and neck surgery, and it has been scarcely reported in the literature. ${ }^{4-7}$ 


\section{Case report}

A 46-year-old woman with disphony for six months, whose diagnosis was squamous cell carcinoma of the larynx (T1N0M0). She had arterial hypotension (100/70 mm Hg) and a 30-year history of smoking approximately one pack of cigarettes per day. In the preoperative evaluation, all the hematological parameters were normal, and the ASA evaluation was II.

The surgical procedure consisted of a horizontal supraglottic laryngectomy with bilateral radical neck dissection and left jugular ligature. It was performed under general anesthesia, in supine position with hyperextension of the cervical spine, and its duration was approximately six hours. During the surgery, blood pressure was measured every 15 minutes, and it ranged between 100/75 and 75/50 $\mathrm{mm} \mathrm{Hg}$, being $90 / 50 \mathrm{~mm} \mathrm{Hg}$ for the last 90 minutes of the procedure. Blood loss was moderate, of approximatly $900 \mathrm{cc}$, and the volume lost by diuresis was $950 \mathrm{cc}$. Replenishment of volume was performed with $2500 \mathrm{cc}$ of crystalloids and $1000 \mathrm{cc}$ of colloids. Hemoglobin and hematocrit during the operation were $10.2 \mathrm{~g} / \mathrm{dL}(12-16 \mathrm{~g} / \mathrm{dL})$ and $29.6 \%(42 \%-52 \%)$ and upon awaking they were $8.7 \mathrm{~g} / \mathrm{dL}$ and $24.7 \%$ respectively. Recovery from anesthesia was uneventful; during the first five hours after the surgery, blood pressure was monitored, and ranged between 110-115/50-55 $\mathrm{mm} \mathrm{Hg}$.

The first day after the surgery, the patient was conscious but sleepy. On the second day, she complained of visual loss in her right eye (RE) and one day later in her left eye (LE). Best-corrected visual acuity (BCVA) was hand movement in the RE and 20/50 in her LE. The pupils were equal in size, but a relative afferent defect was found in the RE.

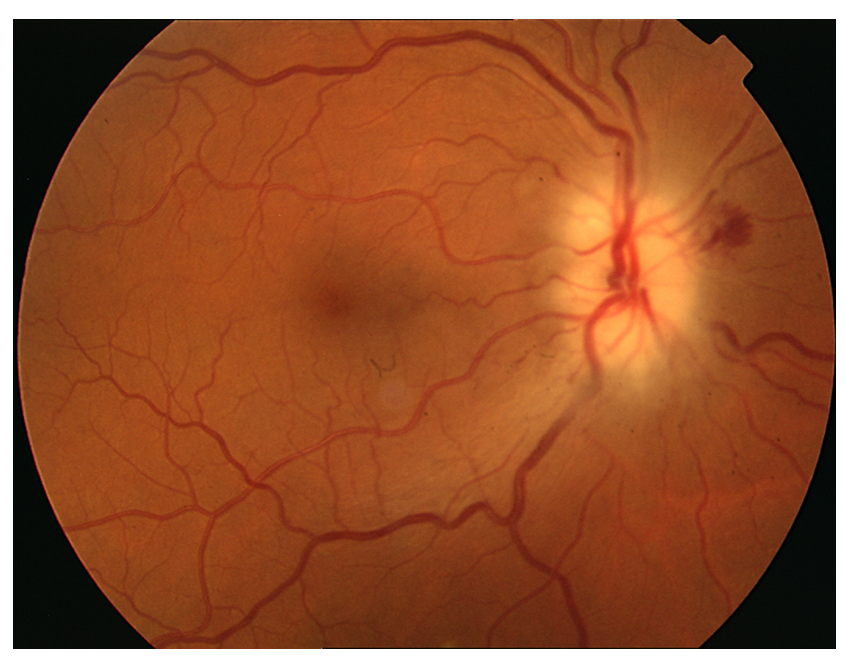

Figure I Swollen optic disc of the right eye with small hemorrhages.
Fundus examination revealed a swollen optic disc with small hemorrhages in the RE and a swollen optic disc in the LE (Figure 1). The laboratory revealed a sedimentation rate of $113 \mathrm{~mm}(20-40 \mathrm{~mm})$, protein C $16.97 \mathrm{mg} / \mathrm{dL}(0.5-2 \mathrm{mg} / \mathrm{dL})$, hemoglobin $9.2 \mathrm{~g} / \mathrm{dL}$, and hematocrit $26.6 \%$. Computed tomography (CT) scan of orbit and brain was normal. The diagnosis was nonarteritic AION, and the patient was treated with methylprednisolone $1 \mathrm{~g}$ for three days, followed by $1 \mathrm{mg} / \mathrm{kg} /$ day for 10 days.

During the following days, several tests were performed. The biopsy of the temporal artery, eco-Doppler of supraaortic trunk and lumbar puncture were normal. The serology for borrelia, syphilis, human immunodeficiency virus, and brucella were all negative, as well as the test for autoimmune diseases and hypercoagulability conditions. Magnetic resonance imaging showed numerous hyperintense supratentorial lesions but none of them in the posterior fossa, no lesion enhanced with contrast, and the optic nerves in $\mathrm{T}_{2}$-weighted tomographies showed no hyperintensity. The Neurology department was consulted and they ruled out demyelinating disease, and attributed the lesions to focal ischemia related to tobacco abuse. Two months later the laboratory data were normal.

VA improved the second day of treatment, rising to $20 / 200$ in the RE and 15/25 in the LE, but on the following days it decreased again to hand movements in the RE. Standard automated perimetry demonstrated complete loss of visual field in the RE, and extensive damage in the LE, in which only a narrow central island of $5^{\circ}$ was preserved (Figure 2). In the following months, the swollen optic disk and hemorrhages disappeared, evolving towards optic nerve atrophy (Figure 3), and the VA decreased to light perception in the RE and 20/70 in the LE. One year after surgery, the VA was light perception in the RE and 20/200 in the LE, and the visual fields remained the same.

\section{Discussion}

Bilateral visual loss after neck dissection is a rare complication, and it is often due to an ION, usually posterior and less frequently anterior. AION involves both eyes when occurring after surgery, presenting with painless visual loss and pallid disc swelling. Posterior ION, on the other hand, has a normal ocular funduscopic appearance, and it is the most commonly seen form of optic neuropathy following head and neck dissection. ${ }^{7}$ In almost all cases of perioperative PION, there has been significant perioperative hemorrhage and hypotension ${ }^{8}$ and one or both eyes have been involved. Clinicopathological studies have demonstrated an infarction in the intraorbital 
Central 30-2, Threshold test

Fixation monitor: Blindspot

Fixation target: Central

Fixation losses: 0/13

False POS errors: 0\%

False NEG errors: N/A

Test duration: 07:06

Fovea: OFF
Stimulus: III, White

Background: 31.5 ASB

Strategy: SITA-Fast
Pupil diameter:

Visual acuity:

RX: + 1.50 DS DC X
Date: $17-04-2008$

Time: 09:35

Age: 46

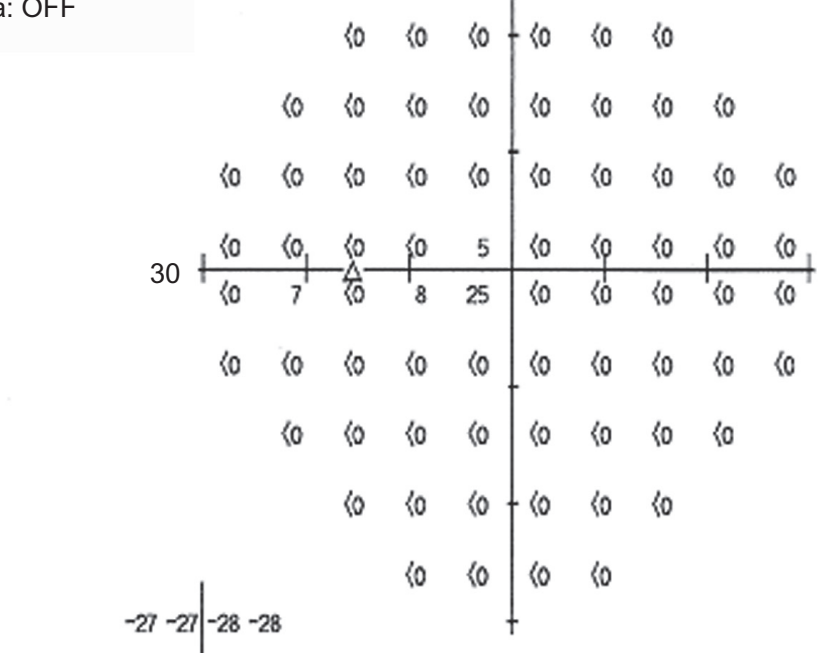

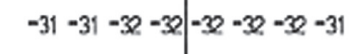

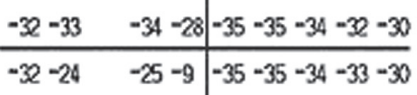

$$
\begin{aligned}
& -32-33-34-34-35-35-35-34-32-30 \\
& -33-33-33-34-34-33-32-31 \\
& -32-32-32-32-32-31 \\
& -32-31 \mid-31-30
\end{aligned}
$$

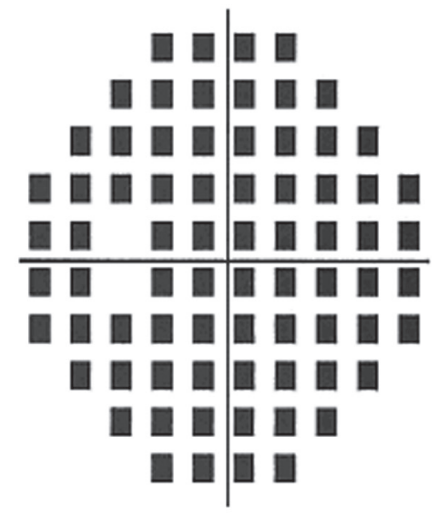

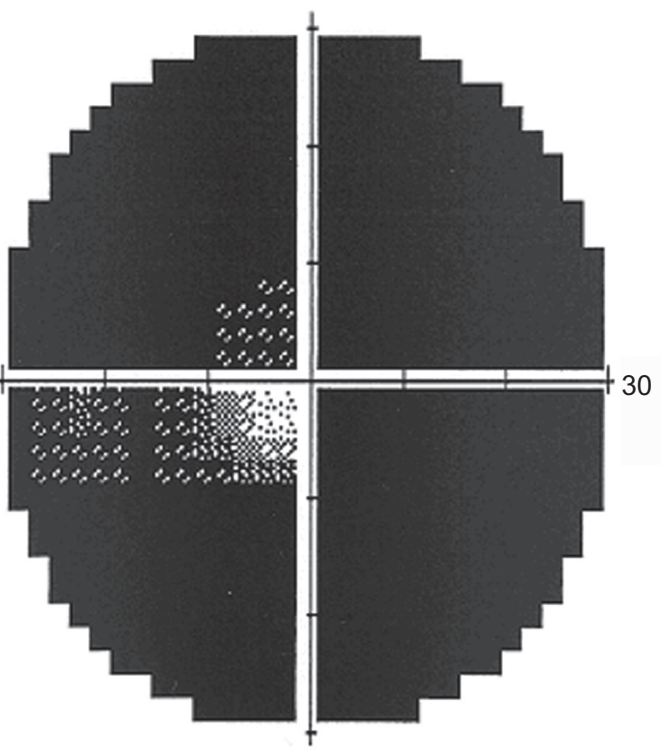

GHP:

Outside normal limits

VFI: $\quad 7 \%$

MD: $\quad-31.95 \mathrm{db} \quad P<0.5 \%$

MSD: $\quad 4.40 \mathrm{db} \quad P<0.5 \%$

Figure 2 Standard automated perimetry demonstrates a preserved central island of $5^{\circ}$. 


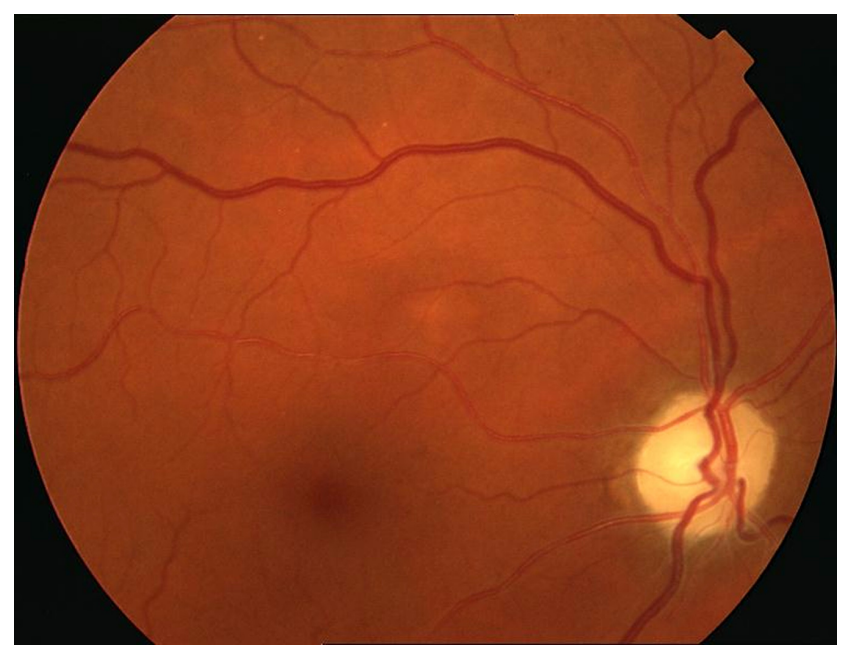

Figure 3 Optic nerve atrophy.

portion of the optic nerve. Blood flow in the orbit is relatively low compared with blood flow to the eye and other portions of the nerve; therefore, this portion of the nerve may be more vulnerable to ischemia due to hypoperfusion. ${ }^{10}$

Perioperative AION is less frequent. There are only four cases reported in the literature after radical neck dissection. ${ }^{6,7,11,12}$ None of them presented severe intraoperative blood loss, although one of the cases presented persistent bleeding in the postoperative period; ${ }^{6}$ none presented arterial hypertension or diabetes mellitus, the most comon risk factors associated with spontaneous AION.

Spontaneous nonarteritic AION usually involves only one eye and typically occurs in patients aged over 50 years. Small cup-to-disc ratio or absence of excavation and optic disc drusen are ocular risk factors associated with AION..$^{13,14}$ Arterial hypertension, nocturnal arterial hypotension, diabetes mellitus, ischemic heart disease, and other cardiovascular disorders, hyperlipidemia, atherosclerosis, and arteriosclerosis are considered systemic risk factors. ${ }^{14,15}$ On the other hand, all published cases of perioperative AION have affected both eyes, often occurring in otherwise healthy patients; it is attributed to a combination of hypovolemia, hemodilution, systemic hypotension, anemia, prone position, and pre-existing cardiovascular disease. ${ }^{13}$

We present a case of bilateral visual loss due to AION after a horizontal supraglottic laryngectomy with bilateral radical neck dissection, in which the patient had preoperative and intraoperative arterial hypotension as the only risk factor. She also had a long history of smoking, a factor also present in the cases reported by Götte and colleagues ${ }^{6}$ and by Strome and colleagues. ${ }^{11}$ In the RNM, our patient had numerous hyperintense supratentorial lesions that were attributed to focal ischemia related to tobacco abuse, possibly indicating a previously disturbed vascular system. Hayreh and colleagues studied the prevalence of smoking among patients with spontaneous AION and found that it was the same as that of the general population, and ruled out smoking as a risk factor for AION. ${ }^{15}$ However, this study was performed on spontaneous AION, which is, in fact, a different situation from perioperative AION.

Perioperative cases of ION are usually related to a combination of hemodynamic derangements. Perioperative anemia and hypotension can lead to a decreased oxygen-carrying capacity of the blood and decreased arterial perfusion pressure. Anemia can result from uncorrected preoperative chronic anemia, intraoperative blood loss and hemodilution, and hypotension from hypovolemia or deliberate hypotension. However, these circumstances are frequent in many surgical procedures, and few patients develop ION, suggesting there must be other associated factors. ${ }^{8}$ Indeed, a case control analysis of 126,666 procedures in which 17 cases of ION were matched with two control patients on whom the same procedure had been performed showed that there were no hemodynamic variables that differed significantly between the patients with ION and the control cases. ${ }^{16}$ Another proposed factor is decreased arterial perfusion pressure secondary to increased orbital pressure, which can be caused by jugular vein ligation and by head-down (Trendelenburg) or prone position. This would explain why this complication is more frequent after radical neck dissection or spinal surgery. ${ }^{8}$ Recently it has been demonstrated that the prone position itself significantly increases intraocular pressure, thereby reducing perfusion pressure in the eye. ${ }^{17}$ Also, defective autoregulation, which can occur with atherosclerotic disease but also with vasospasm and endogenous or pharmacologic vascoconstriction, would account for patient-specific susceptibility, therefore explaining why so few patients develop this complication. ${ }^{8}$

In cases with blood loss, it has been proposed that this circumstance, with or without hypertension, causes an increase in renin and endogenous vascoconstrictors secondary to the activation of the sympatethic system and the vasomotor center. ${ }^{18}$ Another theory proposed by Levin and colleagues is based on the presence of venous congestion. Increased venous pressure, or vasodilatation of the central retinal artery, may compress the central retinal vein and its tributaries within their shared sheath. Venous congestion of the optic nerve parenchyma causes cytotoxic and vasogenic edema, and consequent further compression of the venules feeding the central retinal vein. Venous congestion also 
causes secondary constriction of the small arterioles via the venoarteriolar response, which may aggravate the ischemia, finally resulting in infarction of the nerve. ${ }^{19}$

In radical neck dissection, resection of both internal jugular veins leads to increased intracranial venous pressure with resulting decreased perfusion of the nerve. ${ }^{19}$ The intraocular pressure can also be elevated after this procedure, thereby reducing the perfusion pressure in the optic nerve head even more. Visual loss may be reversible when both internal jugular veins are preserved but permanent when either of them is resected. ${ }^{7}$

In patients undergoing this type of procedure, possible risk factors should be determined and measures to prevent this complication should be taken. High-risk patients should be positioned so that their heads are at the level of the heart or higher. Their heads should be maintained in a neutral forward position, without neck flexion, extension, lateral flexion or rotation. ${ }^{3}$ The use of vasopressors to elevate the blood pressure may cause local constriction of small blood vessels, including those supplying the optic nerves. ${ }^{20}$ Colloids should be used along with crystalloids to maintain intravascular volume in patients who have substantial blood loss. ${ }^{13,21}$ There is no transfusion threshold that would eliminate the risk of perioperative visual $\operatorname{loss}^{18}$ and blood transfusion carries its own set of risks. The ASA general recommendation is that transfusion is indicated when intraoperative hemoglobin is less than six. ${ }^{21}$

Perioperative AION is the one of the few situations in which this condition may be treatable, and the vision loss reversible. ${ }^{11,13}$ Any contributing factors, such as anemia or hypotension, must be aggressively corrected, ${ }^{13}$ although the diagnosis and management of hypotension and anemia do not seem to improve the prognosis of these patients. Most common treatments in nonarteritic AION are corticoids (oral or intravenous bolus), aspirin, and neuroprotectors, such as brimonidine. Recently, intravitreal triamcinolone and bevacizumab have also been used, though neither has been proved beneficial. ${ }^{12,22}$ Only systemic corticosteroid therapy may have a beneficial effect. A recent large, prospective study based on 696 eyes with spontaneous nonarteritic AION concluded that eyes treated during the acute phase with systemic corticosteroids (80 mg prednisone daily for two weeks and then tapering down) had a significantly higher probability of improvement in visual acuity and visual field than did the untreated group. ${ }^{23}$

Head and neck procedures can be considered among the procedures with a risk of POVL. In a large study of more than 500,000 cases (excluding cardiac surgery) in which anesthesia was administered at the Mayo Clinic, two of the four cases of POVL involved radical neck dissection. ${ }^{24}$
Patients undergoing high-risk procedures should be informed that there is a small, unpredictable risk of perioperative visual loss. $^{3}$

In conclusion, our report describes a new case of AION in a patient with arterial hypotension as the only risk factor, who suffered a devastating loss of visual acuity (POVL) following a radical neck dissection.

\section{Disclosures}

The authors have no financial support or commercial interest in this work.

\section{References}

1. Gilbert ME. Postoperative visual loss: a review of the current literature. Neuroophthalmology. 2008;32(4):194-199.

2. Roth S, Thisted RA, Erickson JP, Black S, Schreider BD. Eye injuries after nonocular surgery. A study of 60,965 anaesthetics from 1988 to 1992. Anesthesiology. 1996;85(5):1020-1027.

3. Newman NJ. Perioperative visual loss after nonocular surgeries. Am J Ophthalmol. 2008;145(4):604-610.

4. Gilbert ME, Savino PJ, Sergott RC. Anterior ischemic optic neuropathy after rotator cuff surgery. Br J Ophthalmol. 2006;90(2):248-249.

5. Lee LA, Roth S, Posner KL, et al. The American Society of Anesthesiologists Postoperative Visual Loss Registry: analysis of 93 spine surgery cases with postoperative visual loss. Anesthesiology. 2006;105(4):652-659.

6. Götte K, Riedel F, Knorz MC, Hörmann K. Delayed anterior ischemic optic neuropathy after neck dissection. Arch Otolaryngol Head Neck Surg. 2000;126(2):220-223.

7. Aydin O, Memisoglu I, Ozturk M, Altintas O. Anterior ischemic optic neuropathy after unilateral radical neck dissection: case report and review. Auris Nasus Larynx. 2008;35(2):308-312.

8. Buono LM, Foroozan R. Perioperative posterior ischemic optic neuropathy: review of the literature. Surv Ophthalmol. 2005;50(1):15-26.

9. Fenton S, Fenton JE, Browne M, Hughes JP, Connor MO, Timon CI. Ischaemic optic neuropathy following bilateral neck dissection. $J$ Laryngol Otol. 2001;115(2):158-160.

10. Nawa Y, Jaques JD, Miller NR, Palermo RA, Green WR. Bilateral posterior optic neuropathy after bilateral radical neck dissection and hypotension. Graefes Arch Clin Exp Ophthalmol. 1992;230(4):301-308.

11. Strome SE, Hill JS, Burnstine MA, Beck J, Chepeha DB, Esclamado RM. Anterior ischemic optic neuropathy following neck dissection. Head Neck. 1997;19(2):148-152.

12. Wilson JF, Freeman SB, Breene DP. Anterior ischemic optic neuropathy causing blindness in the head and neck surgery patient. Arch Otolaryngol Head Neck Surg. 1991;117(11):1304-1306.

13. Mathews MK. Nonarteritic anterior ischemic optic neuropathy. Curr Opin Ophthalmol. 2005;16(6):341-345.

14. Hayreh SS. Management of non-arteritic anterior ischemic optic neuropathy. Graefes Arch Clin Exp Ophthalmol. 2009;247(12):1595-1600.

15. Hayreh SS, Jonas JB, Zimmerman MB. Nonarteritic anterior ischemic optic neuropathy and tobacco smoking. Ophthalmology. 2007;114(4):804-809.

16. Holy SE, Tsai JH, McAllister RK, Smith KH. Perioperative ischemic optic neuropathy: a case control analysis of 126,666 surgical procedures at a single institution. Anesthesiology. 2009;110(2):246-253.

17. Hunt K, Bajekal R, Calder I, Meacher R, Eliahoo J, Acheson JF. Changes in intraocular pressure in anaesthetized prone patients. J Neurosurg Anesthesiol. 2004;16(4):287-290.

18. Pazos GA, Leonard DW, Blice J, Thompson DH. Blindness after bilateral neck dissection: case report and review. Am J Otolaryngol. 1999;20(5):340-345. 
19. Levin LA, Danesh-Meyer H. Hypothesis: a venous etiology for nonarteritic anterior ischemic optic neuropathy. Arch Ophthalmol. 2008;126(11):1582-1585.

20. Lee LA, Nothers AB, Sires BS, McMurray MK, Lam AM. Blindness in the intensive care unit: possible role for vasopressors? Anesth Analg. 2005;100(1):192-195.

21. Practice Guidelines for blood component therapy: A report by the American Society of Anesthesiologists Task Force on Blood Component Therapy. Anesthesiology. 1996;84(3):732-747.
22. Ho SF, Dhar-Munshi S. Nonarteritic anterior ischaemic optic neuropathy. Curr Opin Ophthalmol. 2008;19(6):461-467.

23. Hayreh SS, Zimmerman MB. Non-arteritic anterior ischemic optic neuropathy: role of systemic corticosteroid therapy. Graefes Arch Clin Exp Ophthalmol. 2008;246(7):1029-1046.

24. Warner ME, Warner MA, Garrity JA, MacKenzie RA, Warner DO. The frequency of perioperative vision loss. Anesth Analg. 2001;93(6): $1417-1421$.

\section{Publish your work in this journal}

Clinical Ophthalmology is an international, peer-reviewed journal covering all subspecialties within ophthalmology. Key topics include: Optometry; Visual science; Pharmacology and drug therapy in eye diseases; Basic Sciences; Primary and Secondary eye care; Patient Safety and Quality of Care Improvements. This journal is indexed on

\section{Dovepress}

PubMed Central and CAS, and is the official journal of The Society of Clinical Ophthalmology (SCO). The manuscript management system is completely online and includes a very quick and fair peer-review system, which is all easy to use. Visit http://www.dovepress.com/ testimonials.php to read real quotes from published authors. 